\title{
VOLCANIC ASH RETRIEVAL USING A NEW GEOSATIONARY SATELLITE
}

\author{
Kwon H. Lee ${ }^{a, *}$, Kyu T. Lee ${ }^{a}$ \\ a Dept. of Atmospheric \& Environmental Engineering, Gangneung-Wonju National University(GWNU), Gangneung, Korea - \\ kwonho.lee@gmail.com
}

KEY WORDS: Volcanic ash, aerosol, geostationary satellite, GK-2A, MODIS

\begin{abstract}
:
The paper presents currently developing method of volcanic ash detection and retrieval for the Geostationary Korea Multi-Purpose Satellite (GK-2A). With the launch of GK-2A, aerosol remote sensing including dust, smoke, will begin a new era of geostationary remote sensing. The Advanced Meteorological Imager (AMI) onboard GK-2A will offer capabilities for volcanic ash remote sensing similar to those currently provided by the Moderate Resolution Imaging Spectroradiometer (MODIS) satellite. Based on the physical principles for the current polar and geostationary imagers are modified in the algorithm. Volcanic ash is estimated in detection processing from visible and infrared channel radiances, and the comparison of satellite-observed radiances with those calculated from radiative transfer model. The retrievals are performed operationally every $15 \mathrm{~min}$ for volcanic ash for pixel sizes of $2 \mathrm{~km}$. The algorithm currently under development uses a multichannel approach to estimate the effective radius, aerosol optical depth (AOD) simultaneously, both over water and land. The algorithm has been tested with proxy data generated from existing satellite observations and forward radiative transfer simulations. Operational assessment of the algorithm will be made after the launch of GK-2A scheduled in 2018.
\end{abstract}

\section{INTRODUCTION}

Until present, there has been increasing attention on the effects of volcanic ash (VA) on aviation safety [Casadevall, 1992] and human health [Horwell and Baxter, 2006]. Moreover, VA from large volcanic eruptions can increase atmosphere turbidity and the Earth's radiative balance resulting significant natural climate variability [Robock, 2000; Kravitz and Robock, 2011]. It is considered to have been important in the possible influence of climate forcing [Hansen et al., 1992; Kirchner et al., 1999]. VA in the stratosphere also affect the atmospheric chemistry [Grainger and Highwood, 2003; Glasow et al., 2009] and transport processes, leading to ozone depletion [Ramaswamy et al., 1996]. Because of the large scale dispersion and long residence times of VA, notable impacts on the global atmosphere have been reported from the major historical eruptions, such as Mt. Tambora [Rapino et al., 1989], Mt. El Chichón and Mt. Pinatubo [Minnis et al., 1993; McCormick et al., 1995; Kirchner et al., 1999]. In case of Icelandic eruption from the Eyjafjallajökull volcano in 2010, a number of research on VA monitoring, modelling, and its effects have already been published: Langman et al. (2012) discussed overall eruption process and introduced measurement techniques. Johnson et al (2012) observed VA from the aircraft during the eruption, Millington et al (2012) deal with satellite remote sensing and numerical simulation of ash dispersion, and many other references.

For the estimation of VA distribution in atmosphere, many satellite remote sensing techniques have been developed. Widely used method is the reverse absorption (RA) using 10.8 $\mu \mathrm{m}$ and $12.0 \mu \mathrm{m}$ bands developed by Prata et al. (1989). The capabilities and limitations of this method have been discussed in Wen and Rose (1994), Prata et al. (2001) and Pavolonis et al. (2006). Because the RA method is limited over bright surfaces during the daytime [Prata et al., 2001], modified method have been developed, such as the three-bands volcanic ash product
(TVAP) based on the composite of three infrared bands of 3.7 $\mu \mathrm{m}, 10.8 \mu \mathrm{m}$, and $12.0 \mu \mathrm{m}$ [Ellord et al., 2003], multi-channel retrieval for ABI operational algorithm [Pavolonis et al., 2006], and hybrid algorithm based on the composite of RA and TVAP [Lee et al., 2014].

A new geostationary observation sensor, namely the Advanced Meteorological Imager (AMI) onboard the Korea's next-generation geostationary satellite, Korea Multi-Purpose Satellite (GeoKOMPSAT-2A or GK-2A), will observe high spatial and temporal images at sixteen wavelengths from its planned launch in 2018 (see Figure 1). The primary mission of the AMI instrument is monitoring of meteorological phenomena and atmospheric environments.

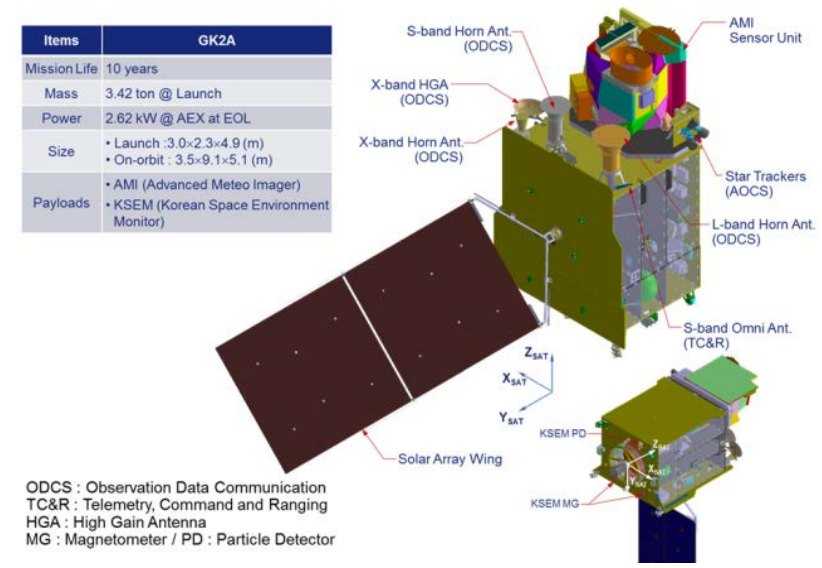

Figure 1. Description of GK-2A mission. It is equipped with Advandced Meteorological Imager (AMI) and Korean Space Environment Monitor (KSEM) payloads (image available from the Korea Aerospace Research Institute (KARI)).

\footnotetext{
* Corresponding author
} 
The AMI instrument is a multispectral instrument; it has merit to estimate VA monitoring from the observed spectral properties of TOA radiance. This study outlines the VA products that will be available from the Korea's next-generation geostationary satellite. Detection and quantitatively retrieving VA properties from the GK-2A multi-channel measurements was investigated. Moreover, this study describes the activities of the GK-2A aerosol retrieval project to help the air quality community prepare for applications of the GK-2A aerosol products. The final objectives of this study include testing new algorithm for the products and estimate any weaknesses or errors associated with the products before the launch of the GK2A satellite.

\begin{tabular}{|c|c|c|c|c|c|c|c|c|c|}
\hline \multirow{2}{*}{\multicolumn{2}{|c|}{ Bands }} & \multirow{2}{*}{$\begin{array}{l}\text { Band } \\
\text { Name }\end{array}$} & \multirow{2}{*}{\begin{tabular}{|c}
$\begin{array}{c}\text { Center } \\
\text { Wavelen } \\
\text { gth }\end{array}$ \\
$\begin{array}{c}\text { Min } \\
\text { (um) }\end{array}$
\end{tabular}} & \multirow[b]{2}{*}{$\begin{array}{l}\text { Max } \\
\text { (um) }\end{array}$} & \multirow{2}{*}{$\begin{array}{c}\text { Band } \\
\text { Width } \\
\text { (Max, } \\
\text { um) }\end{array}$} & \multirow{2}{*}{$\begin{array}{c}\text { Resolut } \\
\text { ion } \\
(\mathrm{km})\end{array}$} & \multirow{2}{*}{ SNR } & \multirow{2}{*}{$\begin{array}{c}\text { NEdT(K) } \\
(240 / \\
300 \mathrm{~K}) \\
\end{array}$} & \multirow{2}{*}{$\begin{array}{c}\text { Radiom } \\
\text { etric } \\
\text { Accura } \\
\text { cy }\end{array}$} \\
\hline & & & & & & & & & \\
\hline \multirow{6}{*}{ VNIR } & 1 & VIS0.4 & 0.431 & 0.479 & 0.075 & 1 & 250 & & $5 \%$ \\
\hline & 2 & VIS0.5 & 0.5025 & 0.5175 & 0.0625 & 1 & 250 & & $5 \%$ \\
\hline & 3 & VIS0.6 & 0.625 & 0.66 & 0.125 & 0.5 & 120 & & $5 \%$ \\
\hline & 4 & VIS0.8 & 0.8495 & 0.8705 & 0.0875 & 1 & 210 & & $5 \%$ \\
\hline & 5 & NIR1.3 & 1.373 & 1.383 & 0.03 & 2 & 300 & & $5 \%$ \\
\hline & 6 & NIR1.6 & 1.601 & 1.619 & 0.075 & 2 & 300 & & $5 \%$ \\
\hline \multirow{5}{*}{ MWIR } & 7 & IR3.8 & 3.74 & 3.96 & 0.5 & 2 & & $\begin{array}{c}3 / \\
0.2\end{array}$ & $1 \mathrm{~K}$ \\
\hline & 8 & IR6.3 & 6.061 & 6.425 & 1.038 & 2 & & $\begin{array}{c}0.4 / \\
0.1\end{array}$ & $1 \mathrm{~K}$ \\
\hline & 9 & IR6.9 & 6.89 & 7.01 & 0.5 & 2 & & $\begin{array}{c}0.37 / \\
0.1 \\
\end{array}$ & $1 \mathrm{~K}$ \\
\hline & 10 & IR7.3 & 7.258 & 7.433 & 0.688 & 2 & & $\begin{array}{c}0.35 / \\
0.12 \\
\end{array}$ & $1 \mathrm{~K}$ \\
\hline & 11 & IR8.7 & 8.44 & 8.76 & 0.5 & 2 & & $\begin{array}{c}0.27 / \\
0.1 \\
\end{array}$ & $1 \mathrm{~K}$ \\
\hline \multirow{5}{*}{ LWIR } & 12 & IR9.6 & 9.543 & 9.717 & 0.475 & 2 & & $0.35 / 0.15$ & $1 \mathrm{~K}$ \\
\hline & 13 & IR10.5 & 10.25 & 10.61 & 0.875 & 2 & & $0.4 / 0.2$ & $1 \mathrm{~K}$ \\
\hline & 14 & $\begin{array}{c}\text { IR11. } \\
2\end{array}$ & 11.08 & $\begin{array}{c}11.3 \\
2\end{array}$ & 1.0 & 2 & & $\begin{array}{c}0.19 / 0 \\
.1\end{array}$ & $1 \mathrm{~K}$ \\
\hline & 15 & IR12.3 & 12.15 & 12.45 & 1.25 & 2 & & $0.35 / 0.2$ & $1.1 \mathrm{~K}$ \\
\hline & 16 & IR13.3 & 13.21 & 13.39 & 0.75 & 2 & & $0.48 / 0.3$ & $1.1 \mathrm{~K}$ \\
\hline
\end{tabular}

Table 1. Channel numbers and wavelengths for the AMI.

\section{DATA AND METHODOLOGY}

\subsection{Instrument overview}

GK-2A is the second generation of Korea's geostationary weather satellites, which will be operating at a longitude of $128.2^{\circ} \mathrm{E}$. GK-2A is scheduled to replace the current geostationary satellite, the Communication, Ocean, and Meteorological Satellite (COMS). As listed in Table 1, the
Advanced Meteorological Imager (AMI) instrument onboard GK-2A will provide new satellite products with higher spatiaotemporal resolution and accuracy. AMI will offer approximately three times more spectral bands and three times more frequent observations of the East Pacific region, and a doubling of spatial resolution compared to the current COMS observation. In detail, AMI has $1 \mathrm{~km}$ resolution visible channel (wavelengths at $0.43 \mu \mathrm{m}, 0.50 \mu \mathrm{m}, 0.63 \mu \mathrm{m}$, and $0.85 \mu \mathrm{m}$ ), near infrared channel (wavelengths at $1.38 \mu \mathrm{m}$ and $1.60 \mu \mathrm{m}$ ) and ten $2 \mathrm{~km}$ resolution infrared (IR) channels (wavelengths at $3.7 \mu \mathrm{m}, 6.1$ $\mu \mathrm{m}, 6.9 \mu \mathrm{m}, 7.3 \mu \mathrm{m}, 8.4 \mu \mathrm{m}, 9.5 \mu \mathrm{m}, 10.3 \mu \mathrm{m}, 11.1 \mu \mathrm{m}, 12.3$ $\mu \mathrm{m}$, and $13.3 \mu \mathrm{m})$. These enhanced geostationary observations can represent a significant increase in the number and quality of forecasting, modeling, and monitoring of VA.

Because GK-2A data are not available, proxy satellite data are required to test VA algorithm. One of the possible way is generating simulated AMI imagery by using radiative transfer model. Currently, we are testing the fast radiative transfer model, RTTOV [Matricardi, 2005; Saunders et al., 1999] to generate forward model results of the AMI radiances. These enable us to generate a rapid simulated satellite imagery in the future. The other method is use of another satellite data having similar band response functions. MODIS has nearly all AMI channel (see Figure 2) and therefore, MODIS Level $1 \mathrm{~b} 1 \mathrm{~km}$ radiance data are used to test the algorithm in this study. Figure 1 shows the relative response function of AMI and MODIS. The datasets used in this study include the MODIS L1b data as proxy data. MODIS L1b (MOD021KM and MYD021KM) data and geometry data (MOD03 and MYD03) were obtained from the NASA LAADS (Level 1 and Atmosphere Archive and Distribution).
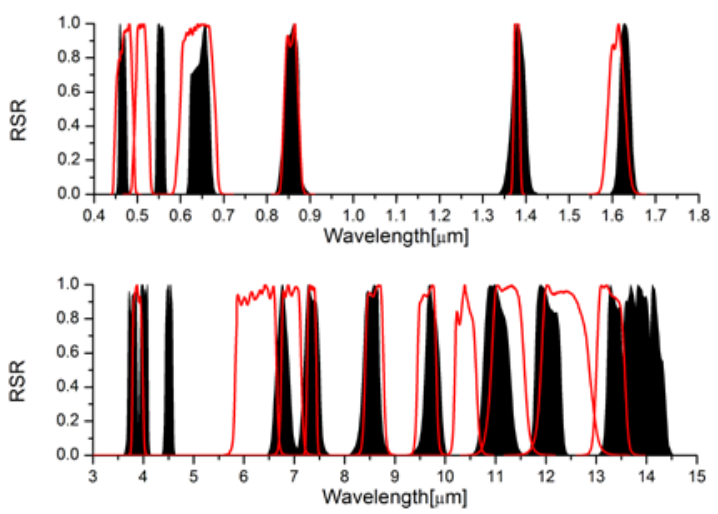

Figure 2. Relative spectral response function of AMI (red lines) and MODIS (black shade).

\subsection{Algorithm description}

VA products for AMI will include VA detection, ash optical depth $(\mathrm{AOD}, \tau)$, and effective radius ( $\left.\mathrm{r}_{\mathrm{eff}}\right)$. AOD is expressed as:

$$
\tau(\lambda)=\int_{z=0}^{T O A} \int_{r=0}^{\infty} \pi r^{2} \cdot Q_{e x t}(\lambda, r) \cdot N(r) d r \cdot d z
$$

where $r=$ particle radius

$\mathrm{Q}_{\mathrm{ext}}=$ extinction efficiency at a given wavelength $\lambda$

$\mathrm{N}(\mathrm{r})=$ particle size distribution 


$$
\text { z = altitude }
$$

The effective radius is area-weighted radius and useful parameter to describe a dominant particle size distribution. Effective radius, reff, is given by equation (2).

$$
r_{\text {eff }}=\frac{\int r^{3} \cdot N(r) d r}{\int r^{2} \cdot N(r) d r}
$$

VA detection product can help distinguish VA from other particles such as smokes or dusts. AOD is a measure of the column integrated extinction of light by ash particles; it is useful for identifying areas of high concentrations of ash particles in the atmosphere. These products can serve to aid both aviation safety and air quality forecasters in classifying VA laden atmosphere. Because satellite receiving radiance is a function of AOD and reff, they can be estimated by solving following radiative transfer equations for visible (equation (3)) [Kaufman et al., 1997] and infrared (equation (4)) [wavelengths.

$$
L_{V i s}^{\text {TOA }}=L_{V i s}^{A e r}\left(\tau, r_{\text {eff }}\right)-L_{V i s}^{\text {Ray }}-\frac{T_{0} \cdot T_{S} \cdot L_{\text {Surf }}}{1-L_{\text {Surf }} \cdot r_{\text {Hem }}}
$$

$$
\begin{aligned}
& \text { where } \quad L_{V / S}^{T O A}=\text { satellite receiving radiance at visible } \\
& \text { wavelength } \\
& L_{V i s}^{A e r}, L_{V i s}^{R a y}, L_{\text {Surf }}=\text { radiance by aerosol, Rayleigh } \\
& \text { scattering, surface reflection. } \\
& T_{0}, T_{S}=\text { transmittances for sun and satellite direction. } \\
& r_{\text {Hem }}=\text { hemispheric reflection } \\
& L_{R R}^{T O A}=\left(1-r_{c}\left(r_{e f f}, \tau\right)\right) B\left(T_{c}\right)+t_{c}\left(r_{e f f}, \tau\right)\left(B\left(T_{s}\right)-B\left(T_{c}\right)\right) \\
& \text { where } L_{R}^{T O A}=\text { satellite receiving radiance at infrared } \\
& \text { wavelength } \\
& \mathrm{B}=\text { plank function } \\
& r_{c}, t_{c}=\text { reflection and transmission of ash cloud. } \\
& T_{c}, T_{s}=\text { ash cloud top and surface temperature }
\end{aligned}
$$

The outline of the data process for the algorithm is summarized in Figure 3. It includes the basic modules of initializing clear sky pixel as an input, conducting a series of tests for cloud screening and VA detection, numerical iteration for VA retrieval and writing the output variables.

It is required for VA algorithm to process the GK-2A observations as quickly as possible in order to provide early warning on the transporting ash plume to forecasters and general public. In this regard, the algorithm for VA detection is supposed to be composed of series of simple tests using nearreal-time observations from satellites, different from the further process of optical and microphysical properties retrieval that need huge look-up-tables (LUTs) and iteration process. In the beginning of the process, sensor quality flag, calibrated/navigated visible reflectance $\left(\rho_{\text {vis }}\right)$ and infrared brightness temperature (BT) on selected channels are used as the sensor input data for the algorithm. For the different spatial resolution of visible channels associated with infrared channels, a reflectance channel data will be averaged to the IR resolution.

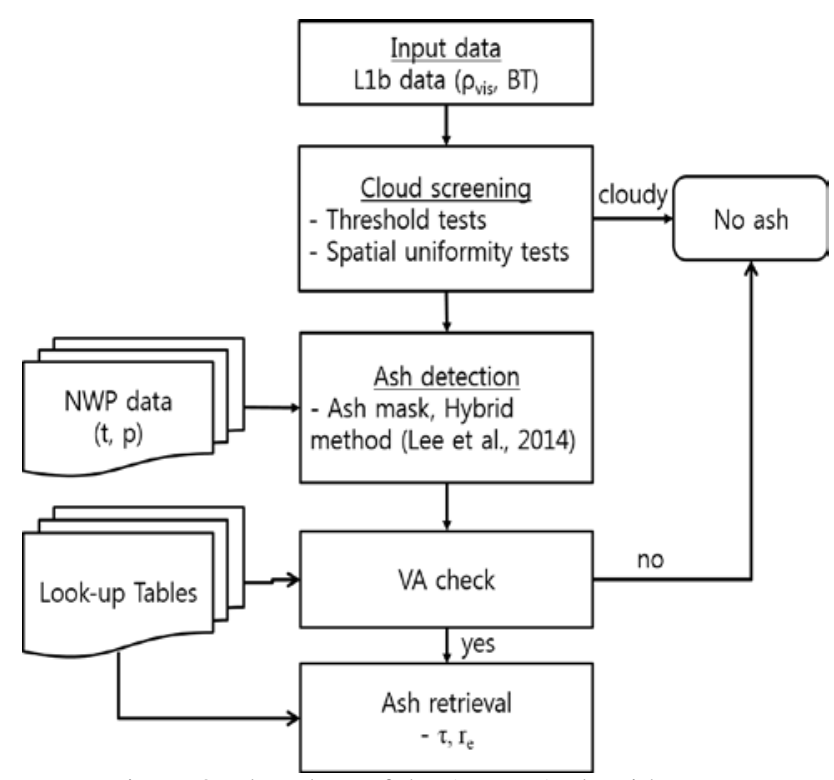

Figure 3. Flowchart of the AMI VA algorithm.

In the next step, cloud mask pixels (if possible, AMI cloud product, snow/ice mask from the AMI level-2 product will be used) including sun glint mask and day/night flag are determined. It should be noted that the cloud screening tests distinguishes cloud and low-aerosol-laden pixels from those with moderate to heavy aerosol conditions. Using observed spectral visible reflectances and infrared BT, the algorithm search for spectral signatures from clouds. The following tests are used to clear sky/cloud detection.

- Sun glint test (over ocean only)

$$
\begin{aligned}
& \Theta_{s g}=\cos ^{-1}\left[\left(\cos \left(\theta_{0}\right) \times \cos \left(\theta_{s}\right)\right)+\left(\sin \left(\theta_{0}\right) \times \sin \left(\theta_{s}\right) \times \cos (\phi)\right)\right] \\
& \text { Sun glint region: } \Theta_{s g}<40^{\circ}
\end{aligned}
$$

where $\Theta_{s g}=$ sun glint angle

$\theta_{0}, \theta_{S}, \phi=$ sun zenith, satellite view, relative azimuth angles.

- Thick cloud test

$$
\rho_{0.4}<0.4, \rho_{0.8}<0.4
$$

where

$$
\rho_{0.4}, \rho_{0.8}=\text { reflectance at } 0.4 \mu \mathrm{m} \text { and } 0.8 \mu \mathrm{m}
$$

- High cloud test

$$
\rho_{1.3}<0.035, B T_{11}<270 K
$$

where

$$
\begin{aligned}
\rho_{1.3} & =\text { reflectance at } 1.3 \mu \mathrm{m} \\
B T_{11} & =\text { brightness temperature at } 11 \mu \mathrm{m}
\end{aligned}
$$

- Spatial uniformity test

$$
\sigma_{3 \times 3}\left(\rho_{0.55}, B T_{11}\right)<0.5 \%
$$

where $\sigma_{3 \times 3}=$ standard deviation of pixel values within a 3 by 3 box centered on a given pixel. 

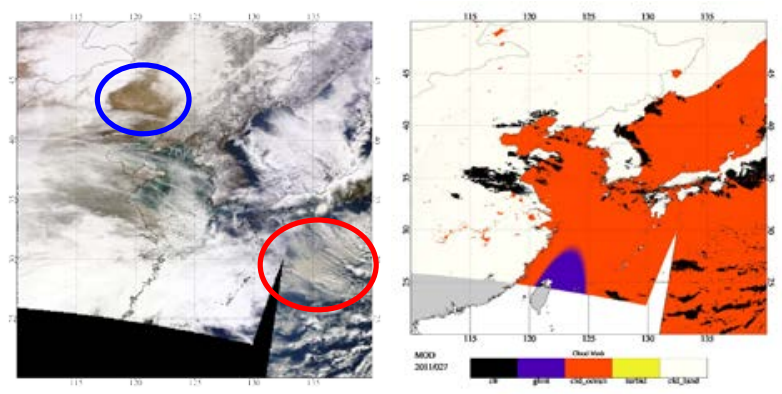

(a)
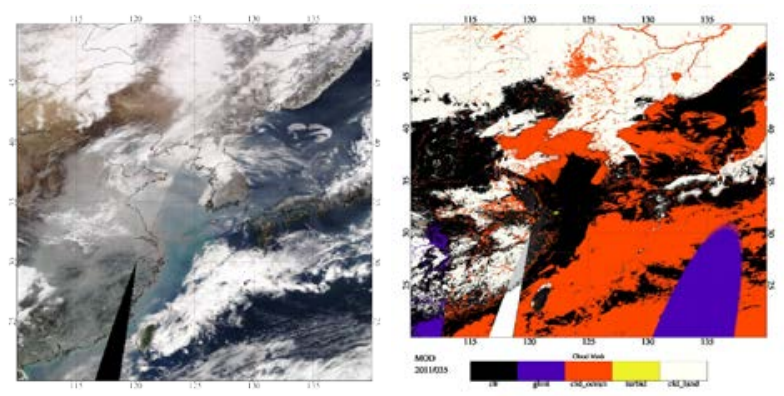

(b)
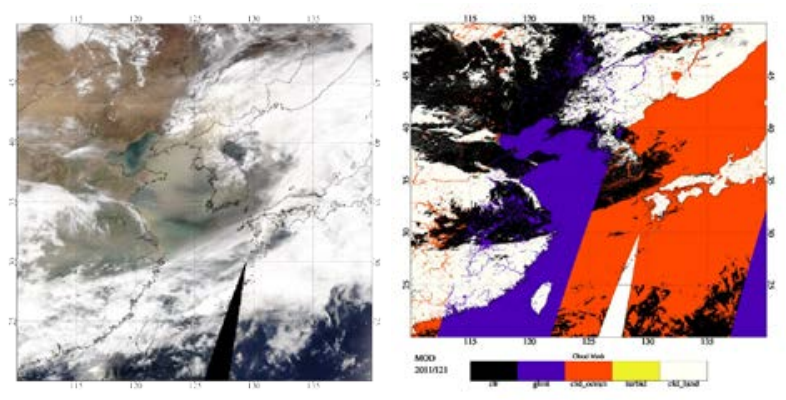

(c)
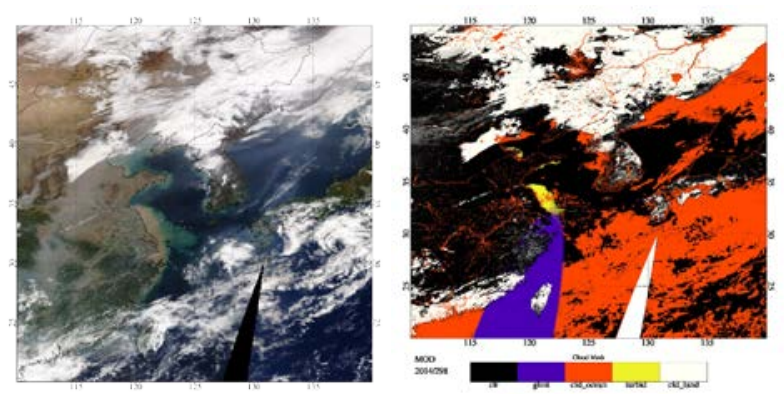

(d)

Figure 4. MODIS $\mathrm{RGB}(\mathrm{R}=4.0 \mu \mathrm{m}, \mathrm{G}=1.6 \mu \mathrm{m}, \mathrm{B}=2.25 \mu \mathrm{m})$ color composite images (left column) and cloud screening results (right column) over region of latitude $20^{\circ}-50^{\circ} \mathrm{N}$ and longitude $110^{\circ}-140^{\circ} \mathrm{E}$. Cases from upper to lower images for (a) volcanic ash case on 27 January 2011, (b) smoke case on 4 February 2011, (c) Asian dust case on 1 May 2011, and (d) relative clear sky case on 25 October 2014, respectively. In the cloud screened image, colors represent clear sky(black), sun-glint region(purple), cloudy over ocean(orange), turbid water(yellow), and cloudy over land (white), respectively. Red and blue circles in (a) indicate ash plume and bright dusty surface in the scene.
To verify cloud screening using above tests, four different aerosol event cases were selected. Figure 4 shows the MODIS red, green, blue ( $\mathrm{R}=0.6 \mu \mathrm{m}, \mathrm{G}=0.5 \mu \mathrm{m}, \mathrm{B}=0.4 \mu \mathrm{m})$ color composite images (left-hand side column) and cloud screened images (right-hand side column). Four different aerosol class over study region (latitude $20^{\circ} \mathrm{N}-50^{\circ} \mathrm{N}$ and longitude $110^{\circ} \mathrm{E}-$ $140^{\circ} \mathrm{E}$ ) were plotted for VA, polluted, dusty, and clean cases. These aerosol classes are visually depicted in the color composite images.

The next step is VA detection. Due to the contrast of VA is different in the atmosphere, calculation of binary flag for aerosol type is possible. Basically, refractive index and relevant size distribution of ash particles in the atmosphere are primary sources of radiative information that can result in different spectral signatures at the top of the atmosphere. For example, VA plumes represent negative BTD (brightness temperature differences) between $\mathrm{BT}_{11}$ and $\mathrm{BT}_{12}$ [Prata et al., 1989] and limited range of TVAP value [Ellord et al., 2003]. In this step, VA pixels are identified by a hybrid method consisting of VA identification and inverse modelling [Lee et al., 2014]. VA pixels are determined by satisfying two independent threshold tests. VA pixel is identified by finding a negative brightness temperature difference (BTD) between $11.2 \mu \mathrm{m}\left(\mathrm{BT}_{11}\right)$ and $12.3 \mu \mathrm{m}\left(\mathrm{BT}_{12}\right)$ channels (equation 9) and three-band BTD (equation 10) at $3.8 \mu \mathrm{m}$ (BT3.8), $10.8 \mu \mathrm{m}$, and $12.0 \mu \mathrm{m}$ wavelengths are used.

$$
\begin{gathered}
\mathrm{BTD}_{11-12}=\mathrm{BT}_{11}-\mathrm{BT}_{12} \\
\mathrm{BTD}_{\mathrm{TVAP}_{1}}=60+10 \times \mathrm{BTD}_{12-11}-3 \times \mathrm{BTD}_{3.8-11} \\
\text { where } \mathrm{BTD}_{12-11}=\mathrm{BT}_{12}-\mathrm{BT}_{11} \\
\mathrm{BTD}_{3.8-11}=\mathrm{BT}_{3.8}-\mathrm{BT}_{11}
\end{gathered}
$$

We used a threshold BTDTVAP value of $70 \mathrm{~K}$ in a hybrid algorithm, which is a BTD-based search and optimization method that minimizes the disadvantages of the two methods by considering diurnal selection. We confirmed that these two tests can discern VA pixels from clouds and other aerosol species in the former study [Lee et al., 2014]. Therefore we added two more tests to minimize ash-like signals from dust or bare soil surface. Because ash-like dust tend to be warmer in the infrared window, brighter in the visible, and less bright in the nearinfrared than VA, shortwave infrared (SWIR) to visible reflectance ratios such as $\rho 1.6 / \rho 0.8<$ Thr1 and (d) $\rho 3.8 / \rho 0.6<$ Thr2 are used These Thr1 and Thr2 are determined from scene based empirical values (see Figure $5 \mathrm{c}$ and $5 \mathrm{~d}$ ). SWIR reflectance at $3.8 \mu \mathrm{m}$ is defined as;

$$
\rho_{3.9}=\frac{L_{3.9}-B\left(B T_{11}\right)}{\frac{1}{\pi} F_{0} \cos \theta_{0}-B\left(B T_{11}\right)}
$$

where $\mathrm{F}_{0}$ is the solar constant for $3.9 \mu \mathrm{m}$,

$\mathrm{B}\left(\mathrm{BT}_{11}\right)$ is the Planck function radiance at $3.9 \mu \mathrm{m}$, which is calculated using the observed $\mathrm{BT}_{11}$.

Bright dusty surface near $43^{\circ} \mathrm{N}$ and $120^{\circ} \mathrm{E}$ shown in Figure 4a shows similar pattern of BTD11-12 and TVAP as shown in Figure $5 \mathrm{a}$ and $5 \mathrm{~b}$. However, the shortwave infrared (SWIR) to visible reflectance (SVR) ratios provides additional quantitative information about the presence of dusty pixels. In Figure $5 c-d$, the SVR ratios are the evidences that the $\rho 1.6 / \rho 0.8$ for VA 
plume tends to be smaller; $\rho 3.8 / \rho 0.6$ for VA plume is larger than dusty pixels.

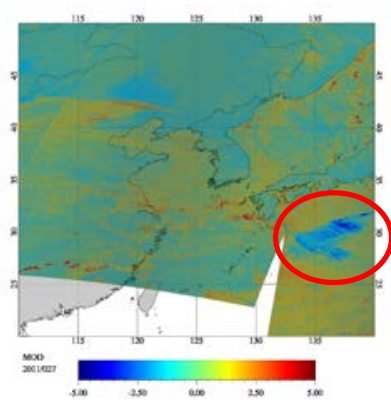

(a)

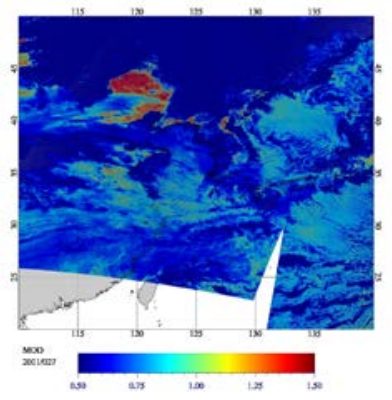

(c)

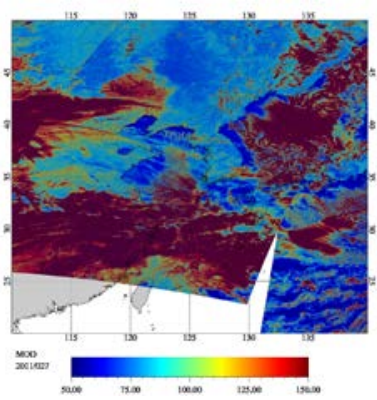

(b)

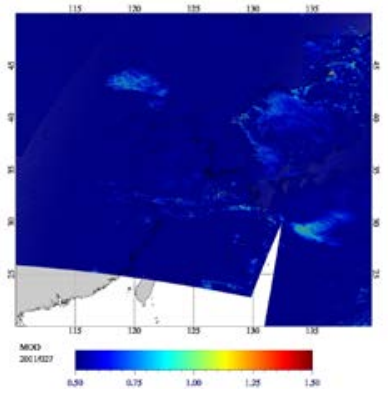

(d)
Figure 5. MODIS derived (a) BTD11-12, (b) TVAP, (c) $\rho 1.6 / \rho 0.8$, and (d) $\rho 3.8 / \rho 0.6$.

In the VA retrieval step, we try to minimize the use of computational resources other than primary sensor data from direct satellite observations by avoiding the large ancillary data that require additional time to process. Typically, remote sensing of VA uses their spectral signatures determined by the inherent optical property (IOP) including complex refractive index and the scattering properties. Those are used to analyse the relationship between theoretical remote sensed radiation calculated by radiative transfer model under various AOD and sun-sensor geometries. AOD can be derived from the minimization of the difference between observed and calculated radiances at different wavelengths using pre-defined VA models which are radiance as a function of AOD, $r_{\text {eff }}$, and ash plume height.

We considered different aerosol type to be separated from VA determined pixels using four aerosol models: dust, smoke, and generic type. The LUTs are the result of simulated radiances using the Santa Barbara DISORT atmospheric radiative-transfer (SBDART) code [Ricchiazzi et al., 1998]. SBDART uses a numerically stable solver for plane-parallel radiative transfer in a vertically inhomogeneous atmosphere. The radiances for VA determined from the former step are then used to derive AOD applying the LUT by the optimum aerosol model. To select the best LUT, iterative selection of the minimum RMSD technique is used. This procedure compares radiance from satellite observation and from various LUTs at a given sun-satellite geometry.

The retrieval of AOT from a measured set of BTs is based on searching for the closest value in the LUT, according to the root-mean-square deviation (RMSD):

$$
\begin{aligned}
\text { RMSD }= & \frac{1}{N_{i}} \sqrt{\frac{\left(B T_{i}^{\text {calc }}-B T_{i}^{\text {obs }}\right)^{2}}{B T_{i}^{\text {obs }}}}+\frac{1}{N_{i}} \sqrt{\frac{\left(B T D_{i}^{\text {calc }}-B T D_{i}^{\text {obs }}\right)^{2}}{B T D_{i}^{\text {obs }}}} \\
\text { where } & \mathrm{BT}^{\text {calc }}=\text { calculated BT by radiative transfer model } \\
& \mathrm{BT}^{\text {obs }}=\text { satellite observed BT } \\
& \mathrm{BTD}^{\text {calc }}=\text { calculated BTD by radiative transfer model } \\
& \mathrm{BTD}^{\text {obs }}=\text { satellite observed BTD }
\end{aligned}
$$

\section{RESULTS}

\subsection{VA detection}

As a case study, we selected the VA plume from eruption Shinmoedake volcano $\left(31.91^{\circ} \mathrm{N}, 130.88^{\circ} \mathrm{E}\right.$, summit elevation $1421 \mathrm{~m}$ ) during January - February 2011. According to the Japan meteorological agency (JMA), VA from the Shinmoedake eruption was first observed at 06:00 UTC on 26 January 2011. The VA plume rose up to 1,500 m above the summit and the Volcanic Ash Advisory Center (VAAC) record showed it reached up to 7,500 m. VA detection was performed for this eruption case to track VA plume. The VA detection is required for clear conditions and uses the spectral detection methods over all pixels. The AOD and $\mathrm{r}_{\text {eff }}$ are only retrieved for non-cloudy areas

Our ash detection technique using MODIS data from the Shinmoedake volcano is shown in Figure 6a-b. The data presented hereafter were acquired on 27 January 2011 during 01:10 UCT - 04:20 UTC for Terra and 04:20 UCT - 06:05 UTC for Aqua. The volcanic ash plume originating from the volcano is well identified, which is of a red colour. That plume is located in the high atmosphere as it is detected by the algorithm explained in section 2.2. On Figure 4a, we show a colour RGB of the same location.

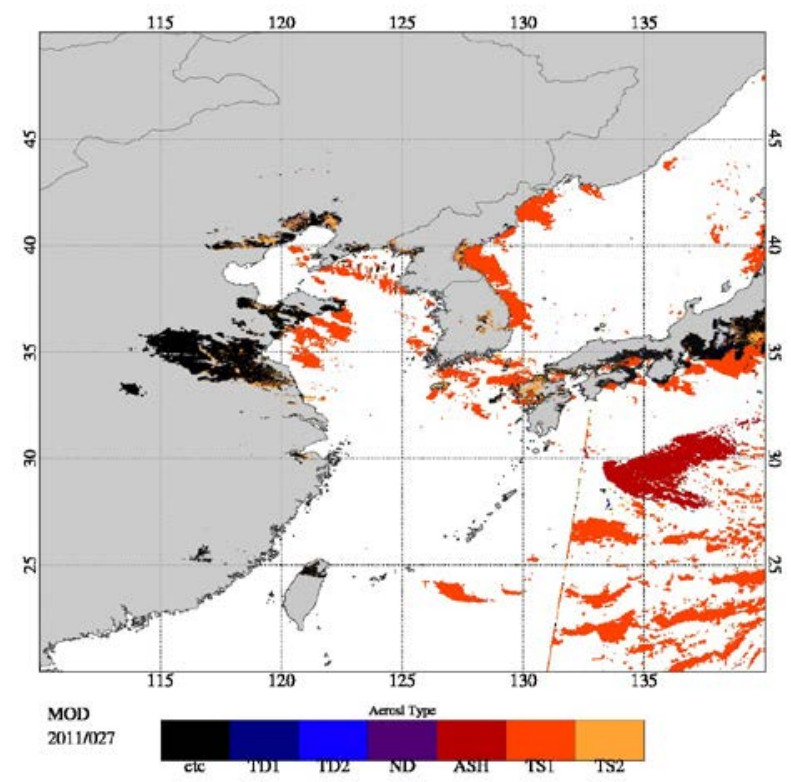

(a) 


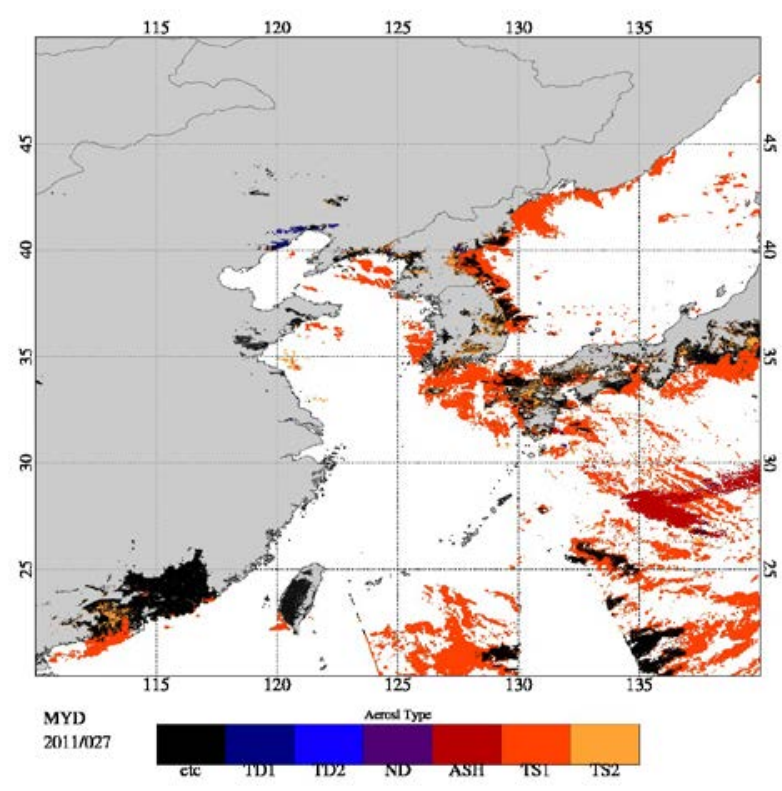

(b)

Figure 6. (a) Terra and (b) Aqua MODIS volcanic ash plume identified by using the VA detection algorithm for the Shinmoedake volcanic eruption on 27 January 2011. The color composite RGB image (top) and aerosol type detection results (down). Colors and abbreviation denote dust (TD1, TD2), nondust(ND), volcanic ash(ASH), and smoke (TS1, TS2), respectively.

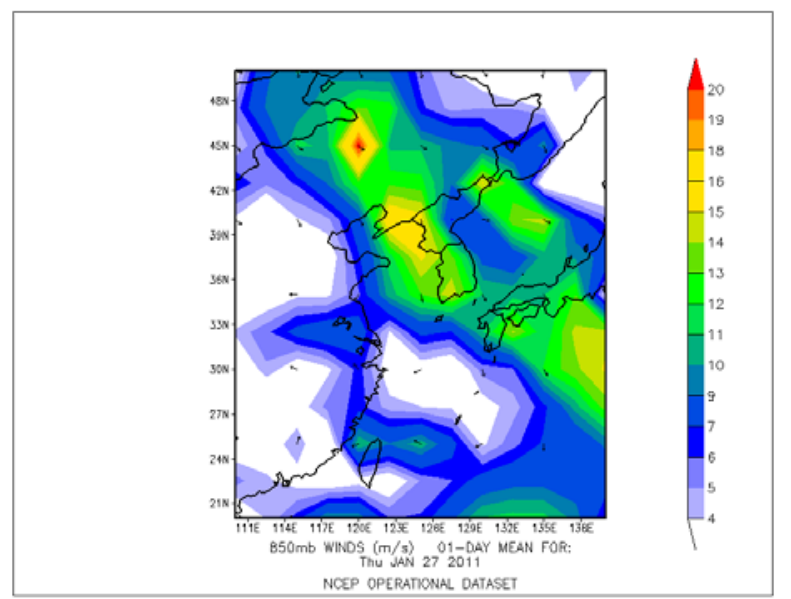

Figure 7. Day mean wind speed and wind vector at $850 \mathrm{hPa}$. Data from NCEP daily analysis product [http://www.esrl.noaa.gov/psd/data/histdata/].

After two hour from the Terra MODIS observation, Aqua MODIS result indicates that the VA emitted from the volcano was transported to the eastward direction. The prevailing wind in this region generally blows from the northwest during this time (see Figure 7). Obviously, geostationary GK-2A observations will be depicted continuous VA observation.

In VA detection with aerosol detection process which will be developed as an independent algorithm, six different aerosol types are plotted for dust(TD1, TD2), non-dust(ND), volcanic ash(ASH), and smoke (TS1, TS2) pixels. These aerosol classes are visually depicted in the different colour pixels. The white pixels in the imagery are null data removed from the algorithm because of the cloudy or bright surface.

\subsection{VA retrieval}

Figure 8a-d show VA retrieval from MODIS after the detection process explained from the former section. Top and bottom panels are results from Terra and Aqua, respectively, and left to right panels represent the height and effective radius. Figure 8a and 8c shows a strong signal from the VA plume in the range of $1.5 \mathrm{~km}-3.5 \mathrm{~km}$. These results are similar to the Cloud-Aerosol Lidar and Infrared Pathfinder Satellite Observations (CALIPSO) extinction profiles from Lee et al., (2014). Collocation of VA height product from satellite and insitu observation is limited, lidar observation data will be useful to validate the heights of GK-2A. Again, the wind direction and plume's dispersion pattern are inferred from these images over a two-hour interval. They were similar to each other, but the extent and range of the plume are different. The wind speed was about $10-13 \mathrm{~m} / \mathrm{s}$ at $850 \mathrm{hPa}$ as shown in Figure 7.

Figure $8 \mathrm{~b}$ and $8 \mathrm{~d}$ shows effective radius patterns from the VA detection product in section 3.1. Upper part of the images from Terra/MODIS contains thick VA plume at higher altitude, while in bottom part there are weak VA cloud clusters. As a result, VA plume patterns are well identified through the method used in this study. And also, the number of pixels from VA clouds is more realistic by the proposed method than by the simple BTD $11-12$ based method.

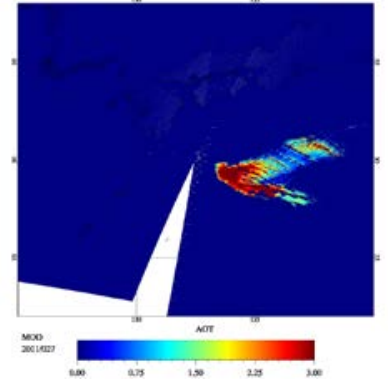

(a)

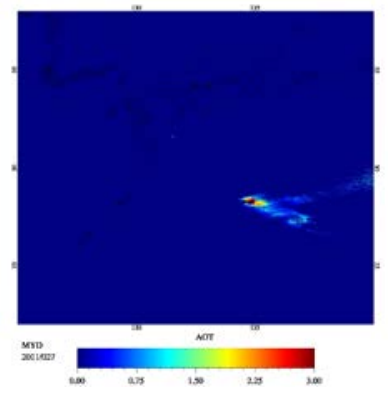

(c)

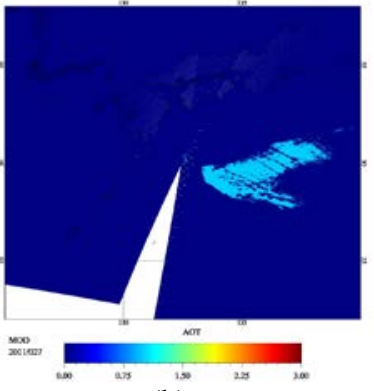

(b)

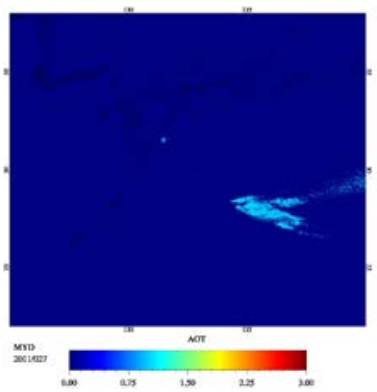

(d)
Figure 8. Volcanic ash plume height (left) and effective radius (right) for Terra (top) and Aqua (bottom) MODIS for the Shinmoedake volcanic eruption on 27 January 2011. Image boundary is rectangular region of latitude $22^{\circ} \mathrm{N}-38^{\circ} \mathrm{N}$ and longitude $125^{\circ} \mathrm{E}-140^{\circ} \mathrm{E}$. 


\section{SUMMARY AND CONCLUSION}

This study shows the detection and retrieval of VA for new geostationary satellite. Based on the radiative-transfer simulations under various physical conditions including loading and size, height, and sun-satellite geometries, the relation between VA and the remote sensed radiance can be understood in a straightforward manner.

The hybrid algorithm for retrieval of VA has been tested for the volcanic eruption cases. The algorithm developed in this study showed that it clearly identified VA pixels with minimal interference from non-volcanic dust, and it provided clear spatio-temporal information about the VA plume.

The VA algorithm for GK-2A/AMI was successfully able to conduct VA products for the northeast Asian region. This study is the first time analysis for the GK-2A proving products. This results will be incorporated into the on-going algorithm development and plans to the next stage for using a radiative transfer simulated proxy data. We are also working with Korea Meteorological Administration (KMA) to develop the prototype algorithm for AMI aerosol products.

\section{ACKNOWLEDGEMENTS}

This work was supported by "Development of Geostationary Meteorological Satellite Ground Segment (NMSC-2014-01)” program funded by NMSC (National Meteorological Satellite Centre) of KMA (Korea Meteorological Administration).

\section{REFERENCES}

Casadevall, T. J., 1992. Volcanic hazards and aviation safety: lessons of the past decade: Federal Aviation Administration Aviation Safety Journal, 2, 3-11.

Ellrod, G. P., Connell, B. H., \& Hillger, D. W., 2003. Improved detection of airborne volcanic ash using multispectral infrared satellite data. J. of Geophys. Res., 108(D12), 4356. doi:10.1029/2002JD00280.

Glasow, von R., N. Bobrowski, C. Kern, 2009. The effects of volcanic eruptions on atmospheric chemistry, Chemical Geology, 263(1-4), 131-142, doi:10.1016/j.chemgeo.2008.08.020.

Grainger, R.G., E.J. Highwood, 2003. Changes in stratospheric composition, chemistry, radiation and climate caused by volcanic eruptions. In: Oppenheimer, C., Pyle, D.M.,Barclay, J. (Eds.), Volcanic Degassing. Geological Society Special Publication No. 213, pp. 329-347.

Hansen, J., A. Lacis, R. Ruedy, and M. Sato, 1992. Potential climate impact of mount Pinatubo eruption, Geophys. Res. Lett., 19(2), 215-218.

Horwell, C.J., and P.J. Baxter, 2006. The respiratory health hazards of volcanic ash: a review for volcanic risk mitigation, Bull. Volcanol., DOI 10.1007/s00445-006-0052-y.

Johnson, B., et al., 2012. In situ observations of volcanic ash clouds from the FAAM aircraft during the eruption of Eyjafjallajökull in 2010, J. Geophys. Res., 117, D00U24, doi:10.1029/2011JD016760.

Kaufman, Y.J., Wald, A.E., Remer, L.A., Gao, B.C., Li, R.-R., Flynn, L., 1997, The MODIS 2.1-mm channel correlation with visible reflectance for use in remote sensing of aerosol, IEEE Transactions on Geosciences and Remote Sensing, 35, 12861298.

Kirchner, I., G. L. Stenchikov, H.-F. Graf, A. Robock, and J. C. Antuña, 1999. Climate model simulation of winter warming and summer cooling following the 1991 Mount Pinatubo volcanic eruption, J. Geophys. Res., 104(D16), 19039-19055, doi:10.1029/1999JD900213

Kravitz, B., Robock, A., 2011. Climate effects of high-latitude volcanic eruptions: role of the time of the year. J. Geophys. Res. 116, D01105.

Langmann, B., A. Folch, M. Hensch, and V. Matthias, 2012. Volcanic ash over Europe during the eruption of Eyjafjallajökull on Iceland, April-May 2010. Atmospheric Environment, 48, 1-8.

Lee, K.H., M.S. Wong, S.-R. Chung, and E. Sohn, 2014. Improved volcanic ash detection based on a hybrid reverse absorption technique, Atmospheric Research, 143, pp. 31-42, http://dx.doi.org/10.1016/j.atmosres.2014.01.019.

Matricardi, M., 2005. The inclusion of aerosols and clouds in RTIASI, the ECMWF fast radiative transfer model for the IASI, Tech Memo 474, Eur. Cent. for Medium-Range Weather Forecasts, Reading, U. K. Eyjafjallajökull in 2010, J. Geophys. Res., 117, D00U24, doi:10.1029/2011JD016760.

McCormick, M.P., L.W. Thomason, and C.R. Trepte, 1995. Atmospheric effects of the Mt Pinatubo eruption, Nature, 373, 399-404.

Millington, S. C., R. W. Saunders, P. N. Francis, and H. N. Webster, 2012. Simulated volcanic ash imagery: A method to compare NAME ash concentration forecasts with SEVIRI imagery for the Eyjafjallajökull eruption in 2010, J. Geophys. Res., 117, D00U17, doi:10.1029/2011JD016770.

Minnis, P., Harrison, E., Stowe, L., Gobson, G., Denn, F., Doelling, D., and W. Smith, 1993. Radiative climate forcing by the Mount-Pinatubo eruption, Science, 259, 1411-1415.

Pavolonis, M. J., Feltz, W. F., Heidinger, A. K., \& Gallina, G. M., 2006. A daytime complement to the reverse absorption technique for improved automated detection of volcanic ash. Journal of Atmospheric and Oceanic Technology, 23, 14221444. doi: http://dx.doi.org/10.1175/JTECH1926.1.

Prata, A.J., 1989. Observations of volcanic ash clouds in the 10-12-micron window using AVHRR/2 Data, Int. J. Remote Sens.,10, 751-761.

Prata, A.J., G.J.S. Bluth, W.I. Rose, D.J. Schneider, A.C. Tupper, 2001. Comments on "Failures in detecting volcanic ash from a satellite-based technique”, Remote Sens. Environ., 78, pp. 341-346.

Ramaswamy, V., Schwarzkopf, M.D., Randel, W.J., 1996. Fingerprint of ozone depletion in the spatial and temporal 
pattern of recent lower stratospheric cooling, Nature, 382, 616618.

Rampiro, M.R., M.S. Newton, and J.A. Wolff, 1989. Volcanonological study of the great Tambora eruption of 1815, Geology, 12, 659-663.

Ricchiazzi, P., S. Yang, C. Gautier, and D. Sowle, 1998. SBDART: A research and teaching software tool for plane parallel radiative transfer in the earth's atmosphere, Bull. Amer. Meteor. Soc., 79, 2101-2114.

Robock, A., 2000. Volcanic eruptions and climate, Rev. Geophys., 38(2), 191-219, doi:10.1029/1998RG000054.

Saunders, R. W., M. Matricardi, and P. Brunel, 1999. An improved fast radiative transfer model for assimilation of satellite radiance observations, Q. J. R. Meteorol. Soc., 125, 1407-1425, doi:10.1002/qj.1999.49712555615.

Wen, S. and Rose, W.I., 1994. Retrieval of sizes and total mass of particles in volcanic clouds using AVHRR bands 4 and 5. J. of Geophys. Res., 99(D3), 5421-5431. 